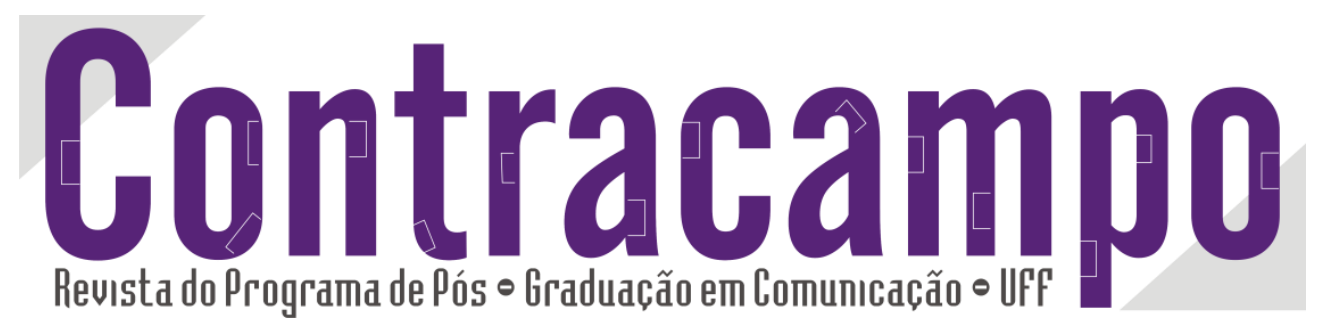

\title{
O produtivo tempo livre dos jovens: representações do consumo do tempo na contemporaneidade
}

\author{
The Productive Leisure Youth: \\ representations of time consumption in contemporary
}

Júlia Salgado

juliasalgado@gmail.com

Jornalista pela Escola de Comunicação da UFRJ.

Mestre e Doutoranda no PPGCOM/UFRJ, na linha Mídias e Mediações Socioculturais.

Ao citar este artigo, utilize a seguinte referência bibliográfica

SALGADO, Júlia. O produtivo tempo livre dos jovens: representações do consumo do tempo na contemporaneidade. In: Revista Contracampo, v. 24, n. 1, ed. julho, ano 2012. Niterói: Contracampo, 2012. Pags: 233-248.

\section{PPGCOM $=$ UFF}

\section{Edição 24/2012}

Temáticas diversas

Contracampo

Niterói (RJ), v. 24, n. 1, jul./2012.

e-ISSN 2238-2577 www.uff.br/contracampo

A Revista Contracampo é uma revista eletrônica do Programa de PósGraduação em Comunicação da Universidade Federal Fluminense e tem como objetivo contribuir para a reflexão crítica em torno do campo midiático, atuando como espaço de circulação da pesquisa e do pensamento acadêmico. 


\section{Resumo}

Este artigo pretende investigar as recentes transformações nos usos do tempo livre juvenil. Diante da observação de representações midiáticas que encenam adolescentes empreendendo e produzindo em seus momentos de lazer e diversão, sugerimos poder estar presenciando 0 crescimento e a naturalização de uma mentalidade empreendedora entre os jovens. Não mais apenas detentores do direito de consumir, torna-se recorrente, no discurso midiático, a legitimação de um dever de produzir entre os adolescentes nem que seja a subjetiva produção de si como capital humano a ser aperfeiçoado. Tal hipótese se edifica diante da observação do consumo do tempo livre juvenil encenado e retratado na mídia; tempo livre este que se torna tanto mais valorizado quanto mais produtivo seja. Para embasar a argumentação, fazemos uma análise comparativa de duas séries de TV voltadas para o público jovem, complementando-as, ainda, com matérias jornalísticas.

Palavras-chave: juventude; empreendedorismo; mídia.

\section{Abstract}

This paper proposes an investigation on the recent changes in the use of leisure time by youth. Given the observation of media representations that stage adolescents undertaking and producing in their moments of leisure and fun, we suggest that we could be witnessing the growth and naturalization of a entrepreneurial mindset among young people. No longer just holding the right to consume, it become recurrent in the media speech the legitimacy of a duty to produce among adolescents - even if it's a subjective production of the self as human capital to be perfected. This hypothesis is based on the observation of the youth free time played on TV series or portrayed in newspaper articles; free time that becomes more valuable as more productive it is. To support this argument we present a comparative analysis of two television series aimed at young audiences, complementing them with journalistic pieces.

Keywords: youth; entrepreneurship; media. 
$W$ e All Want to Be Young. Este é o título do filme ${ }^{1}$ de aproximadamente dez minutos produzido pela Box $1824^{2}$, uma requisitada - e jovem - empresa de consultoria na área de tendências de comportamento e consumo. $\mathrm{O}$ vídeo, que mescla teorias acadêmicas ${ }^{3}$ com preceitos mercadológicos num formato hollywoodiano (usando cenas de filmes e clipes, músicas famosas e peças publicitárias), defende a máxima de que são eles, os jovens, os irradiadores de comportamentos e práticas de consumo em nossa contemporânea sociedade. E que, portanto, para entender $\mathrm{o}$ futuro do comportamento, o futuro do consumo e até mesmo o futuro da sociedade (!) é para eles, jovens, que devemos mirar.

We All Want to Be Young mostra como os jovens de hoje, intitulados de millennials, são a "primeira juventude global": através de ferramentas de conectividade como a Internet e os telefones celulares, os millennials têm total acesso ao mundo, independente de seu local de origem. Essa ampla e ubíqua conectividade estaria, segundo a hipótese, influenciando a própria identidade da atual juventude:

Determinadas pela internet, suas identidades transcendem o lugar de onde são. Isso não está acontecendo por pura coincidência. O consumo globalizado promove conexões estéticas e comportamentais com outros jovens ao redor do mundo. (...) Essa consciência coletiva é o zeitgeist do futuro, levando a um cenário de oportunidades. (...) Mais do que nunca, para entender o mundo é preciso entender esses jovens, que são os catalisadores das grandes mudanças (trechos do vídeo We All Want to Be Young).

Estando ou não de acordo com as hipóteses defendidas pela empresa de consultoria - que, evidentemente, sobrecarrega suas afirmações com interesses mercadológicos -, acreditamos que existe uma importante conexão entre consumo e

\footnotetext{
${ }^{1}$ Disponível em http://www.youtube.com/watch?v=9yEsgbR1oVI. Último acesso em: 29/02/2012.

${ }^{2}$ http://www.box $1824 . c o m \cdot b r /$

3 Ao longo do filme, podemos identificar a apropriação de várias teses ligadas à sociologia, à antropologia, à comunicação e à história ao case "juventude+consumo+comportamento". Alguns exemplos são: uma revisão da teoria "trickle-down", de Simmel (1971), trocando a posição de status social por "status de idade"; os imperativos por decisão, responsabilidade, superação pessoal e alto desempenho - e as consequentes inseguranças e ansiedades crônicas advindas desses imperativos, questões abordadas por diversos autores como Ehrenberg (2010), Sennett (2010) e Bauman (1998, 2011), entre outros; as vantagens e desvantagens conquistadas a partir de um mundo regulado pela tecnologia, onde para alguns se acredita estar vivendo na "era da inteligência coletiva" (Lèvy, 1993), e da conectividade ubíqua (Jenkins, 2009; Boltansky\&Chiapello, 2009).
} 
identidade (Campbell, 2006). Seguindo o raciocínio de alguns estudiosos, notadamente o sociólogo Colin Campbell e a psicóloga Lúcia Rabello de Castro, compreendemos o consumo como uma atividade que, entre outras coisas, atua na constante construção identitária de cidadãos-consumidores, e que, portanto, tem muito a nos revelar sobre a sociedade em que vivemos. Outras abordagens frisam a importância dos meios de comunicação - em conjugação com o consumo - como regentes de subjetividades e formadores de identidade (BACCEGA e CASTRO, 2009). Não à toa nos propomos, aqui, analisar alguns discursos midiáticos, e suas relações com consumo, cidadania, subjetividade e produção.

Em um primeiro momento, encarar os cidadãos como consumidores - ou os consumidores como cidadãos - tem menos a ver com as capacidades adquiridas pelos consumidores de transformar seu ato de consumo em estratégias de resistência aos poderes hegemônicos do mercado do que com a similitude da lógica que impregna ambos os campos (de consumo e de cidadania): a lógica da livre escolha (FREIRE FILHO, 2008). É sob este estandarte maior do neoliberalismo que pessoas comuns devem aprender a ser bons consumidores - diante da vasta oferta de produtos, é preciso saber filtrar, selecionar, enfim, escolher - e, ao mesmo tempo, bons cidadãos - sabendo, igualmente, escolher os caminhos a seguir, as decisões a serem tomadas, as diretrizes que vão guiar seu corpo e seu tempo.

Para Bauman (2008), trata-se da reconfiguração de nossas relações, em sociedade, a partir daquilo que aprendemos como consumidores: "o ambiente existencial que se tornou conhecido como 'sociedade de consumidores' se distingue por uma reconstrução das relações humanas a partir do padrão, e à semelhança, das relações entre os consumidores e os objetos de consumo." (BAUMAN, 2008: 19). Como cidadãos de uma realidade crescentemente desregulamentada e fluida, somos levados a assimilar nossos aprendizados da esfera do consumo também na vida em sociedade: aprendemos a calcular a relação custo/benefício dos objetos, mas valorizamos aquilo que nos satisfaz e realiza, de forma que utilitarismo e desejo (ou, como diria Featherstone, "hedonismo calculista") se misturam em nossas escolhas pessoais. E assim, também nas práticas cidadãs de nosso dia-a-dia, aprendemos a escolher aquilo que nos serve, que nos é útil, sem, contudo, abandonar a satisfação de nossos mais íntimos desejos, que podem incluir também a preocupação com a prosperidade coletiva 
- ainda que se tenha disseminado a noção de que as maiores preocupações atuais são autocentradas e não comunais.

No caso específico dos jovens, grupo de interesse deste artigo, a relação entre consumo e identidade e cidadania se torna ainda mais relevante, à medida que o primeiro aparece como condição de formação do segundo e de existência do terceiro. As práticas de consumo (que incluem o consumo midiático) ocupam cada vez mais um papel central na construção identitária dos adolescentes, que têm a possibilidade de perceber "quem realmente são" a partir daquilo que gostam, desejam, experienciam. A identidade, assim, pode ser continuamente formada e lapidada através do consumo material e simbólico. E esse contínuo consumo, como defende Campbell, mais do que simplesmente ajudar na formação do $e u$ contemporâneo, atua no sentido de prover-lhe uma segurança ontológica:

Assim, embora a exposição a uma vasta gama de bens e serviços ajude a nos dizer quem somos (por permitir que expressemos nossos gostos), essa mesma exposição exerce a função ainda mais vital de nos convencer de que nosso self é de fato "autêntico" ou "real". Dessa forma, enquanto o que desejo (e também o que não gosto) me ajuda a me dizer quem sou, o fato de eu desejar intensamente ajuda a me convencer de que realmente existo. (CAMPBELL, 2006: 57).

Por outro lado, o consumo também aparece como protagonista quando refletimos sobre a hodierna forma de pensar a cidadania - e aqui, em especial, pensar os jovens como cidadãos. Como nos lembra Lúcia Rabello de Castro, a infância e a adolescência tinham papeis secundários na sociedade moderna, que entendia esses sujeitos como "pré-cidadãos" ou "sujeitos em formação". Estando, em sua maioria, à parte dos processos produtivistas do mundo industrial, às crianças e aos adolescentes cabia esperar que o período preparatório passasse para que pudessem, na maturidade, integrar a sociedade como cidadãos de direitos e deveres (o que, para os propósitos deste artigo, entenderemos como sendo sujeitos produtores/consumidores, devendo produzir e com direito a consumir). No entanto, a partir do momento em que passamos de uma sociedade que exerce a socialização de seus entes através da produção (sociedade de produtores) para uma sociedade que o faz pelo consumo (sociedade de consumidores), abre-se caminho para que outros atores - como os jovens - sejam admitidos dentro da trama social, não apenas em estado gerúndio (se preparando, se 
formando...), mas também de forma ativa e presenteísta. Como defende a autora, tratase da emancipação da criança e do adolescente através do consumo.

Dessa forma, não mais como "futuros cidadãos", os novos sujeitos consumidores usufruem de reconhecimento social, e de um lugar indisputável na cultura, agora não mais invisíveis por não poderem trabalhar ou produzir, mas eminentemente agentes, porque podem consumir. Neste sentido, a criança e o jovem aparecem, adquirindo potência e agência, enquanto novos atores no cenário da cultura contemporânea. (CASTRO, 1998: 60).

Deste primeiro salto posicional, localizado em meados do século XX e com o qual grande parte dos jovens ocidentais passa do estado de pré-cidadãos para o de cidadãos-consumidores (ou, ainda, cidadãos de direitos, pois podem consumir), talvez possamos hoje falar de um segundo salto. Este estaria transformando os jovens “cidadãos de direito" também em "cidadãos de deveres", através da naturalização de uma mentalidade produtiva e empreendedora entre os adolescentes. Não mais apenas detentores do direito de consumir, torna-se recorrente no discurso midiático a naturalização de um dever de produzir entre crianças e adolescentes - nem que seja a subjetiva produção de si como capital humano a ser moldado e aperfeiçoado.

Tal hipótese se edifica diante da observação do consumo do tempo livre juvenil (encenado em séries televisivas ou retratado em matérias jornalísticas); tempo livre este que se torna tanto mais valorizado quanto mais produtivo seja. Para embasar esta argumentação, trazemos uma análise comparativa ${ }^{4}$ de duas séries televisivas voltadas para o público jovem (Confissões de Adolescente e Ger@1.com), complementando-as, ainda, com matérias jornalísticas que tratam sobre juventude e empreendedorismo.

\section{Os objetos analisados}

Em 1992, um produto cultural voltado para os jovens é lançado com espantoso sucesso: Confissões de Adolescente, livro que depois vira peça teatral, série de TV e filme, tem seu enredo baseado nas vivências, dilemas e práticas corriqueiras de quatro

\footnotetext{
${ }^{4}$ A análise televisiva aqui empreendida é discursiva, ou seja, centra-se na relação estabelecida entre texto (os discursos em si) e contexto (o ambiente sociocultural de cada temporalidade retratada) (Shohat e Stam, 2006), não se preocupando com um exame estético das obras. O corpus audiovisual selecionado contempla todos os 20 episódios da primeira temporada de Confissões de Adolescente (material lançado em DVD em 2005) e os 10 episódios das duas temporadas de Ger@l.com (a primeira temporada foi lançada em DVD em 2010, enquanto os episódios da segunda temporada nos foram gentilmente cedidos pela Rede Globo).
} 
jovens irmãs na ali referida "perturbada" fase da adolescência. Assuntos até então muitas vezes interditos para esse público - como sexo, drogas, aborto, política e inseguranças individuais - viram mote para capítulos, atos e episódios. O seriado televisivo, lançado na TV Cultura em 1994, conta a história de quatro irmãs adolescentes (Diana, 19 anos; Bárbara, 17 anos; Natália, 15 anos e Carol, 13 anos) que, órfãs ou abandonadas pelas respectivas mães, vivem com o pai na Zona Sul do Rio de Janeiro. De forma genérica, é um seriado que aborda questões cotidianas e de relacionamentos, quer sejam familiares, quer sejam interpessoais relativos ao mundo juvenil.

Quinze anos depois, outro produto midiático voltado para os adolescentes chega ao mercado: Ger@l.com. A Internet e as correlatas ferramentas de comunicação fornecem a base sobre a qual a narrativa do programa se desenvolve e em que as questões sobre juventude florescem. A minissérie, de apenas cinco episódios em cada temporada, faz uso de uma linguagem na qual realidade e ficção se misturam ao tratar das aventuras de cinco adolescentes de 13 anos que produzem um site de compartilhamento de músicas, fotos, vídeos, testes etc. Os jovens Rita, Neca, Jô, Junior e B Menor criam o site LigaGer@1.com para compartilhar vídeos, músicas, arquivos e fotos, além de chatar (com texto, voz ou vídeo) através das ferramentas de conectividade. As suas aventuras começam quando decidem ajudar a banda teen $\mathrm{WWW}^{5}$ a ensaiar e gravar seu primeiro clipe, que seria postado na Internet, aumentando assim as suas chances de sucesso.

A escolha dos dois produtos acima descritos se justifica não apenas por se tratar de representações midiáticas sobre a juventude ${ }^{6}$ em duas temporalidades diversas, o que nos possibilita comparar temas e abordagens julgados pertinentes por seus enunciadores, seja em meados da década de 1990, seja nos dias atuais ${ }^{7}$. Mas também por serem representações que, dialogando com assuntos e práticas familiares à vida

\footnotetext{
${ }^{5} \mathrm{O}$ nome da banda tem origem no sobrenome de seus integrantes, todos da família Werneck. Mas não deixa de ser interessante a ligação entre o nome e a sequência de letras mais digitada pela juventude hoje. ${ }^{6} \mathrm{~A}$ adolescência específica a qual faremos referência durante todo o trabalho é aquela que se desenha nas duas séries: jovens brancos, entre 10 e 19 anos, de classe média-alta e moradores da cidade do Rio de Janeiro.

${ }^{7}$ No caso de Confissões de Adolescente, o contexto social, temporal e geográfico para a construção do discurso é: família liberal de classe média-alta da Zona Sul do Rio de Janeiro (mais especificamente Arpoador) no início da década de 1990. Geral.com também apresenta um quadro semelhante: adolescentes de classe média-alta da Zona Oeste do Rio de Janeiro (mais especificamente Barra da Tijuca) no final da década de 2000.
} 
corriqueira desta adolescência específica, parecem almejar um status de maior proximidade com esses atores (diferentemente, por exemplo, de produtos como Armação Ilimitada (1985/88) ou Hannah Montana (2006/10), que, ao fazerem uso de fantasia e situações improváveis em suas narrativas, afastam-se da pretensão de querer representar um mundo verossímil). Nosso empreendimento será o de compreender os possíveis motivos que podem levar esses enunciadores a privilegiar uma imagem da juventude tal qual se apresenta nas séries aqui analisadas, e como essa representação se conecta com apreciados valores sociais, culturais e econômicos.

Tempo livre: consumo ou produção?

O tempo livre pode ser compreendido, em um primeiro momento, segundo sua acepção mais corrente: é o "tempo que sobra do horário de trabalho e/ou do cumprimento de obrigações, aproveitável para o exercício de atividades prazerosas" (Houaiss, 2009). Em oposição ao tempo produtivo, quando é preciso seguir regras e normas a fim de cumprir as tarefas determinadas (e não escolhidas), é no consumo do tempo livre que o sujeito pode realizar-se, satisfazer seus mais íntimos desejos, enfim, "ser ele mesmo". O tempo livre, portanto, é o tempo do entretenimento, do lazer, do sagrado (Rocha, 1985), da consumação romântica de nossas sensibilidades e nossos desejos íntimos (Campbell, 2001). Campbell afirma que todo ato de consumo é também ato de construção: "podemos estar tanto 'consumindo', no sentido de uma experiência, quanto 'construindo', por meio de produtos, uma determinada identidade, ou ainda nos 'autodescobrindo"' (CAMPBELL, 2006: 23). Qual é, desse modo, a identidade dos jovens construída a partir do consumo que fazem de seu tempo livre nas séries estudadas?

No seriado da TV Cultura o tempo livre é gasto com certa despreocupação e despudor: diversas cenas ilustram as jovens em sonolentas tardes na frente da televisão, em desatentos e vagarosos jogos de tabuleiro ou carta, em longas conversas telefônicas ou simplesmente na praia, banhando-se ao sol com as irmãs e amigas. Percebe-se que o "não fazer nada", ou gastar o tempo livre com atividades objetivamente improdutivas (ver TV, jogar, conversar, dormir...) não é, no seriado, moralmente objetável, ainda que também não seja louvado. Mais precisamente, poderia ser considerada uma justa pausa, 
como num pit stop de corrida automobilística, para a recarga das energias gastas na sequência de atividades diárias: escola, cursos de línguas, de dança, esportes, deveres de casa etc. Seguindo uma moralidade do "eu mereço", consumir o tempo livre a seu bel prazer equilibraria - ou compensaria - a árdua e constante tarefa de termos de ser produtivos e eficientes, seja no trabalho ou na escola.

Esses tempos livres, consumidos em geral com atividades de diversão e entretenimento, são também utilizados pelas personagens para "pensar na vida", "refletir sobre as escolhas tomadas" e, conversando com terceiros, "debater ideias e percepções". O ócio, aqui, não deixa de ser criativo, como sugeriria Domenico De Masi (2000), ainda que neste primeiro momento seja pouco difundida a fértil (e atual) associação entre criatividade e produtividade. Mais importante, contudo, é perceber ao longo da série uma nítida separação entre os momentos de lazer e aqueles de produção, como se a natureza do primeiro fosse de água e a do segundo de óleo. Ou seja: podem até se encontrar, mas não se misturam.

Ociosidade, entretanto, não é um substantivo constante no dicionário dos jovens deGer@l.com. A maior prova disto é pensar no uso que fazem de seu tempo, que é livre, já que estão de férias. Ao invés de atividades puramente prazerosas e hedonistas, como ver televisão, brincar e jogar, tomar sol e fofocar, vemos jovens usando seu tempo de lazer em tarefas produtivas. Jô, Rita, Neca, Júnior e B Menor constroem e fazem a manutenção de seu site, o LigaGer@1; ajudam os meninos da banda WWW a achar um lugar para ensaiar e também os ajudam a gravar clipes de suas músicas e postá-los na Internet, tornando-os notórios; articulam estratégias de resistência aos mandos e desmandos da síndica de seu condomínio e ainda organizam formas de mobilização em prol do camping onde mora o pai da personagem Rita. Os jovens músicos da WWW, por sua vez, ensaiam e criam novas músicas, gravam clipes e se submetem a sessões fotográficas, e ainda se predispõem a tocar em um festival em favor da salvação do camping. Isso sem falar no jovem Júnior, compulsivo produtor de vídeos para a Internet e que, na segunda temporada, ainda convence seus pais a salvar a falida lanchonete do condomínio, onde passa a ajudar como garçom.

O uso do tempo livre em atividades produtivas não é, porém, valorado como chato ou penoso. Muito ao contrário, o que vemos é a busca da sinergia entre tarefas que sejam, ao mesmo tempo, producentes e divertidas, criativas e lúdicas, frutíferas e 
prazerosas. Os jovens se divertem ao gravar clipes e vídeos, sem esquecer que sua consequente postagem na Internet pode lhes render vantagens como convites para shows ou para fechar contratos. Fazer a constante manutenção do site LigaGer@1 alimentando-o com novas músicas, fotos ou enquetes - é, a um só tempo, forma otimizada de expressão pessoal de gostos e preferências e, também, caminho para conquista de novos e numerosos acessos (acessos estes que, aliás, têm se tornado requerido valor dentro e fora da cultura juvenil). Da mesma maneira, organizar e produzir o festival que vai arrecadar dinheiro para salvar o camping da bancarrota é "a coisa mais maneira que já aconteceu nos últimos tempos".

Na mídia impressa vemos, com certa recorrência, o enaltecimento de jovens que fazem um uso produtivo de seu tempo livre. Seja nas retóricas acerca de jovens empreendedores, que usam as tardes e os finais de semana para montar "pequenos negócios com grandes pretensões"; seja nas exaltações sobre o uso do tempo livre para o aperfeiçoamento (em geral através de cursos ou de maneira autodidata) do maior capital de qualquer adolescente - ele mesmo! -, o fato é que a mídia vem contribuindo para essa nova significação dos bons usos do tempo livre juvenil.

Em 10 de novembro de 2010 a revista Veja Rio $^{8}$ dedica uma página inteira à história do prodígio Pedro Henrique, menino de 14 anos que cria aplicativos para iPhone e já trabalha, três vezes por semana, como consultor de novos projetos em uma empresa de tecnologia. A reportagem avalia seu desempenho escolar, concluindo, nas entrelinhas, que ser um bom aluno no colégio não é a única via de promoção ao sucesso: dedicar seu tempo livre à computação legitima-se sobre os estudos.

Seu desempenho escolar não chega a ser brilhante. Nas aulas, concentra-se o máximo possível para passar de ano sem estudar muito. Por razões óbvias, prefere matemática e ciências, disciplinas em que gabarita as provas. Mas detesta história e redação (apesar disso tirou nota 8,7 em ambas no último bimestre). Nas horas de lazer, porém, as diferenças em relação aos coleguinhas aparecem em cores mais vivas. Enquanto eles jogam videogame, futebol e gostam de colecionar figurinhas, Pedro Henrique adora ficar... no computador. (VEJA Rio, $10 / 11 / 2010)$

A construção de si, crescentemente empreendida pelos jovens em seus horários livres, também é pauta recorrente. Ainda a revista Veja, em edição especial dedicada

\footnotetext{
${ }^{8}$ Disponível em: http://vejabrasil.abril.com.br/rio-de-janeiro/editorial/m2150/o-pequeno-notavel. Acesso em: 25/11/2010.
} 
aos jovens em setembro de 2001, aponta uma tendência aparentemente ubíqua na juventude brasileira: o superlotamento de suas agendas. Com o apropriado subtítulo "Os adolescentes de hoje têm agenda de diretor de multinacional", a reportagem "Tudo ao Mesmo Tempo" aborda de maneira bastante atenuada os possíveis perigos de uma rotina juvenil cheia de compromissos: caberia aos pais a responsabilidade de bem organizar a pletora de tarefas de seus filhos, e não minimizá-la:

Balé, inglês, esgrima, alemão, musculação e squash, além das aulas normais. Todas essas atividades fazem parte da agenda da paranaense Krissia Kamile Singer Wallbach, de apenas 13 anos. Ela não é exceção. É regra. "Um dos traços distintivos dos jovens dos dias de hoje é que eles pertencem a uma geração com agenda superlotada", avalia a publicitária Wilma Rocca, uma estudiosa do comportamento jovem. De quem é a culpa? Em geral de pais e filhos. É próprio do adolescente querer experimentar tudo. Somem-se a isso pais cada vez mais preocupados com que seus filhos possuam diferenciais na guerra futura do mercado de trabalho. (...) Não há nada de errado em tentar proporcionar aos filhos uma boa educação. O problema é o exagero. Alguns jovens se empenham em fazer tudo-ao-mesmo-tempo-agora que isso acaba afetando a saúde e o desempenho na escola. É responsabilidade dos pais ajudar os filhos a organizar horários. (VEJA Especial Jovem, setembro de 2001, grifos nossos)

Também na web podemos perceber um movimento de ressignificação do tempo consumido por crianças e jovens. O blog de tecnologia Techtudo, do Portal G1, inicia a reportagem "Top 11: crianças e jovens empreendedores" com as seguintes declarações: "Ser criança, para alguns, é brincar com os amigos sem se preocupar com o tempo, comer e dormir. Porém, com as possibilidades oferecidas pela Internet, vários meninos e meninas já iniciaram seus projetos e estão faturando alto”. Em seguida, são contadas 11 histórias de sucesso cujos protagonistas são jovens empreendedores. Como "o caso emblemático Sean Belnick":

Em 2001, com apenas 14 anos, o menino trancou-se por três dias em seu quarto e saiu de lá com a ideia da empresa BizChair.com, uma companhia virtual especializada em venda de móveis de escritório. Para dar o pontapé inicial, Sean pegou US\$ 500 emprestados com o seu padrasto, que também seria o "construtor" das encomendas, criou o site e pagou a hospedagem. Em 2010, a empresa atingiu a impressionante marca de US\$ 58 milhões em vendas. E pensar que tudo isso começou no quarto de um garoto de 14 anos. ${ }^{9}$

\footnotetext{
${ }^{9}$ Disponível em http://www.techtudo.com.br/rankings/noticia/2012/01/top-11-criancas-e-jovensempreendedores.html. Último acesso em 29/02/2012.
} 
A união de produção e prazer não é, no entanto, uma novidade. Ao lembrar a influência do trabalho em nossas vidas, Campbell aponta para

(...) o número de horas gastas nesses processos, a sempre crescente preocupação com a produtividade, o reconhecimento da importância da dimensão simbólica no universo organizacional e do surgimento e valorização de uma ética hedonista de trabalho, que o privilegia enquanto expressão da criatividade e da individualidade de cada um. Uma ética que predomina e define justamente aqueles segmentos que se diz fazerem do consumo seu principal mecanismo de reprodução social: classes médias, yupies, intelectuais, profissionais liberais, entre outros. (CAMPBELL, 2006: 24).

Casaqui e Riegel, em artigo sobre a publicização midiática do ambiente de trabalho na Google, mostram como a empresa cria sua imagem no mercado a partir do ambiente que oferece aos seus funcionários. Legitimando a criatividade, a diversão e o valor da experiência no ambiente de trabalho, a Google traria para a esfera produtiva características comuns ao campo do consumo:

O mundo do trabalho, identificado no cenário do Google com significações de criatividade, despojamento, modernidade e juventude, torna-se espetáculo que sublima o caráter competitivo e demais conotações negativas associadas a essa esfera de atuação humana. (...) Trabalho e consumo, dessa forma, unem-se no mesmo campo simbólico, com a predominância na manifestação dos sentidos do consumo que mercadoriza a imagética do mundo do trabalho no contexto dos serviços tecnológicos de nosso tempo. A criatividade não seria tão percebida pela concretude dos produtos gerados quanto pela identificação com a espacialidade e com os dispositivos inseridos no ambiente da atividade profissional. (CASAQUI e RIEGEL, 2009: 163)

Essas ponderações mostram a contemporânea tendência de trazer para os momentos de trabalho características tradicionalmente estranhas a ele - ludismo, experimentação, imprevisibilidade e livres associações. O imaginário criado em Ger@l (e também em outros discursos midiáticos), no entanto, apresenta um movimento ao mesmo tempo contrário e complementar a essa tendência. Ao invés de vermos aspectos prazerosos invadirem o campo da produção, detectamos práticas de criação e empreendimento tomarem espaço nos momentos de lazer, transformando-os em situações de realização prazerosa. Certamente esta dinâmica não atua sozinha. Ao contrário, sugerimos que seja uma complementação (ou uma retroalimentação) da tendência sinalizada por Campbell, Casaqui e Riegel: da mesma maneira que as horas 
laboriosas são impregnadas de aspectos hedonistas, os momentos de prazer se tornam produtivos. E assim os jovens encenados naturalizam, desde cedo, a não distinção entre horário de trabalho e de lazer, produzindo e se divertindo sempre.

Chegamos, portanto, ao ponto que nos interessa investigar - investigação esta, diga-se de passagem, ainda seminal e passível de reflexões. Em que pese a vantagem de viver num mundo onde a diversão e o entretenimento permeiam todos os momentos da vida (Gabler, 1999), para esses jovens tornam-se absolutamente normais demandas e modos de ação empresariais, como a ubíqua disponibilidade, a flexibilidade, o apetite pelo lucro, a manutenção de elos (Boltanski e Chiapello, 2009). Familiarizados com um léxico e com lógicas oriundos dos ambientes de trabalho, as crianças e os jovens de hoje são estimulados (pela família, pela escola e pela mídia) a gerenciar seu tempo, administrar os recursos disponíveis, dedicar-se às inúmeras atividades, exercer liderança entre os amigos, obter resultados dentro (e fora) do ambiente escolar e, não menos importante, empreender a todo e qualquer momento, pois não o fazendo é sabido que a responsabilização por qualquer percalço que a vida profissional pode oferecer é individual, e não coletiva (Salgado, 2011). A sugestão de que os jovens hoje viveriam sob o imperativo de um "tempo otimizado" e que deve ser bem investido e aproveitado nos leva a refletir sobre o que, de fato, consistiria o valor desse tempo. Ou seja: quais são as lógicas que definem o tempo como melhor ou pior aproveitado? Melhor - ou pior - para quem e para quê?

$\mathrm{Na}$ tentativa de responder a estas questões sem desconsiderar o nosso objeto de estudo - os jovens -, seguiremos a linha de raciocínio desenvolvida por Rocha, Pereira e Balthazar (2010). No artigo intitulado "Tempo Livre é Tempo Útil: gadgets, entretenimento e juventude", os autores relativizam algumas tradicionais noções de uso do tempo, como a noção desenvolvida por Veblen (1995) do tempo ocioso como símbolo de status e distinção social, assim como a utilitarista noção moderna de tempo útil, como aquele empregado única e exclusivamente para fins de produção. Eles propõem, em contrapartida, um novo valor do tempo pela perspectiva juvenil perspectiva esta que também se apropria da tecnologia como instrumento de esmaecimento entre as esferas "diversão e obrigação", "entretenimento e trabalho", "livre e útil". Com as tecnologias de comunicação e informação (em especial os gadgets que reúnem em si diversas funções, "úteis" ou não) os jovens associariam a liberdade e 
o prazer do entretenimento à utilidade e à necessidade da produção em um só momento, tornando, assim, o tempo otimizado.

Portanto, é legítimo refletir sobre os usos do tempo entre os jovens mais ainda, sobre o valor útil do tempo. O tempo livre, do qual convencionalmente se espera um uso hedonista, sobretudo relacionado à vivência do prazer e da felicidade, é o contraponto do que entendemos por tempo útil, essencialmente produtivo, pragmático e objetivo. Consequentemente, o lazer estaria relacionado ao tempo livre e o trabalho, por sua vez, ao tempo útil. Relativizando, porém, o determinismo desta idéia, é importante lembrar que a cultura do bemestar, produto da ética individualista moderno-contemporânea, vem promovendo o entretenimento a um novo patamar. Os gadgets, por serem também aparelhos capazes de desempenhar esse papel, ocupam um lugar central de transformação ao diluir as fronteiras do tempo, aproximando, cada vez mais, prazer e trabalho, felicidade e rotina. (ROCHA, PEREIRA e BALTHAZAR, 2010: 9).

Assim, poderíamos sugerir uma atual lógica de legitimação do tempo juvenil, aquela do tempo criativo. $\mathrm{O}$ adjetivo criativo é aqui usado pela sua capacidade de conter em si os aspectos lúdicos e prazerosos de uma ação inovadora, original ou simplesmente nova, e também o lado ativo - ou ainda, profícuo - de criar, conceber. Parafraseando o título do artigo acima citado, aproveitar bem o tempo para os jovens hoje seria aproveitá-lo de forma livre (prazerosa, que entretém) e, ao mesmo tempo, de forma útil (ativa, produtiva).

Ao consumir seu tempo livre com atividades não puramente hedonistas, como acontece em Confissões, mas associando produtividade aos momentos de prazer, a identidade que se constrói em Ger@l é aquela de jovens proativos e dinâmicos, empreendedores e flexíveis. Produção e consumo se tornam indissociáveis, sendo cada vez mais difícil separar as práticas de cada esfera. Nesse sentido, enquanto percebemos os dois grupos de jovens igualmente envoltos na busca pela diversão, em Ger@l os adolescentes ganham uma significação social mais empoderadora, já que não apenas consomem (tempo livre, bens materiais e simbólicos), mas também produzem a partir do seu consumo.

Resta-nos, finalmente, deixar uma indagação sobre o real valor deste empoderamento juvenil conquistado a partir das contemporâneas práticas produtivas dos mesmos. Tal empoderamento, em princípio, remete ao aumento de poder e acúmulo de habilidades necessárias para exercer determinada atividade, associando à imagem de um jovem empreendedor atributos como autonomia, proatividade, criatividade e 
sucesso. Porém, vendo sob outra perspectiva, poderíamos também pensar o mesmo empoderamento como um fardo, resultante de um aumento de deveres e um acúmulo de responsabilidades destes sujeitos que são estimulados, desde cedo, a produzir, seja um conteúdo, seja um produto, seja seu próprio capital humano.

\section{Conclusão}

Chegamos ao momento em que, mais do que apontar para alguma conclusão final e determinante, é preciso iniciar um questionamento sobre as condições que possibilitam e incitam uma crescente apropriação do tempo livre pela esfera produtiva, e não o contrário, como previam (ou, ao menos, desejariam), alguns sociólogos do trabalho, como Domenico de Masi (1999). Além deste primeiro e essencial questionamento, de ordem mais ampla e social, cabe a nós, pesquisadores da comunicação, compreender como a mídia vem se posicionando diante desta nova reconfiguração dos usos do tempo por parte da juventude. Pois ao encenar representações da juventude que naturalizam e glorificam o uso do tempo livre para atividades empreendedoras e produtivas, sugiro que nos casos analisados a mídia atuou no sentido de legitimar uma nova configuração social e subjetiva dos jovens e seus tempos. A saber: de um tempo (e uma subjetividade juvenil) tanto mais valorizado quanto mais produtivo seja.

\section{Referências bibliográficas}

BACCEGA, Maria Aparecida e CASTRO, Gisela. Comunicação e consumo: cidadania em perigo? Revista da ESPM, vol. 16, p. 56-60, jul/ago 2009.

BARBOSA, Lívia e CAMPBELL, Colin. (orgs.). Cultura, consumo e identidade. Rio de Janeiro: Editora FGV, 2006.

BAUMAN, Zygmunt. Vida para consumo. Rio de Janeiro: Jorge Zahar Ed., 2008.

O mal estar da pós-modernidade. Rio de Janeiro: Jorge Zahar Ed., 1998.

Vite che non possiamo permetterci. Roma: Editori Laterza, 2011.

BOLTANSKI, Luc e CHIAPELLO, Ève. O novo espírito do capitalismo. São Paulo: Martins Fontes, 2009. 
CAMPBELL, Colin. A ética romântica e o espírito do consumismo moderno. Rio de Janeiro: Rocco, 2001.

CASAQUI, Vander e RIEGEL, Viviane. Google e o consumo simbólico do trabalho criativo. Comunicação Mídia e Consumo, vol. 6, nº17, p. 161-180, 2009.

CASTRO, Lúcia Rabello (org.) Infância e adolescência na cultura do consumo. Rio de Janeiro, NAU: 1998.

DE MASI, Domenico. O ócio criativo. Rio de Janeiro: Sextante, 2000.

Il futuro del lavoro. Milano, Rizzoli, 1999.

EHRENBERG, Alain. $O$ culto da performance: da aventura empreendedora a depressão nervosa. São Paulo: Editora Idéias \& Letras, 2010.

FREIRE FILHO, João. Mídia, Subjetividade e Poder: Construindo os Cidadãos-Consumidores do Novo Milênio. Lugar Comum: estudos de mídia, cultura e democracia. $\mathrm{N}^{\mathrm{o}}$ 25-26, p. 89-103, 2008.

GABLER, Neal. Vida, o filme: como o entretenimento conquistou a realidade. São Paulo: Companhia das Letras, 1999.

JENKINS, Henry. Cultura da convergência. São Paulo: Aleph, 2009.

LÉVY, Pierre. As tecnologias da inteligência. São Paulo: Editora 34, 1993.

ROCHA, Everardo. Magia e Capitalismo. São Paulo: Brasiliense, 1985.

ROCHA, Everardo, PEREIRA, Claudia e BALTHAZAR, Ana Carolina. Tempo livre é tempo útil: gadgets, entretenimento e juventude. In: XIX Encontro da Compós. Rio de Janeiro: PUCRio, 2010.

SALGADO, Julia. A cultura do empreendedorismo nos discursos sobre a juventude. In: $X X$ Encontro da Compós. Porto Alegre, 2011. V. 1, p. 1-15.

SENNETT, Richard. A corrosão do caráter: consequências pessoais do trabalho no novo capitalismo. Rio de Janeiro: Record, 2010.

SHOHAT, E. e STAM, R. A crítica da imagem eurocêntrica. São Paulo: Cosac Naify, 2006.

SIMMEL, George. On individuality and social forms. Chicago: University of Chicago Press, 1971.

VEBLEN, Thorstein. A teoria da classe ociosa. Rio de Janeiro: Abril, 1995. 